\title{
Foxp3 downregulation in NSCLC mediates epithelial-mesenchymal transition via $\mathrm{NF}-\kappa \mathrm{B}$ signaling
}

\author{
XI WANG, YING LIU, LINGLING DAI, QI LIU, LIUQUN JIA, HUAN WANG, LIN AN, \\ XIAOGANG JING, MENG LIU, PENGFEI LI and ZHE CHENG \\ Department of Respiratory Disease, The First Affiliated Hospital of Zhengzhou University, \\ Zhengzhou, Henan 450000, P.R. China
}

Received March 10, 2016; Accepted August 9, 2016

DOI: $10.3892 /$ or.2016.5024

\begin{abstract}
Forkhead box P3 (Foxp3) is a member of forkhead box transcription factor family and it was identified as a tumor suppressor in various solid tumors. This study evaluated the expression of Foxp3 in non-small cell lung cancer (NSCLC) and investigated its role in epithelial-mesenchymal transition (EMT) of cancer cells. qRT-PCR and western blot analysis were used for examining the expression of Foxp3 in NSCLC tissues and the non-tumor tissues. A tissue microarray was constructed and scored for evaluating the clinical significance of Foxp3 expression in NSCLC tissues. RNAi was employed for downregulating Foxp3 expression and cell proliferation was done with MTT assay. Transwell with or without basement membrane matrix was used for cell migration and invasion assay respectively. Foxp3 was found downregulated in NSCLC tissues compared with non-tumoral tissues; downregulation of Foxp3 predicted adverse tumor stage and overall survival; silencing of FOXP3 promoted the proliferation, migration and invasion ability of NSCLC cells and influenced the expression level of EMT-associated proteins. However, forced expression of Foxp3 could reverse this effect. Moreover, Foxp3 could interact with LMO2 and affect the expression level of TAL1, which was in accordance with the findings in T-cell acute lymphoblastic leukemia. By screening the signalling pathways, we observed an obvious upregulation of phosphorylated NF- $\mathrm{\kappa B}$ in A549 and H520 cells after silencing of FOXP3. Our results suggest that Foxp3 suppressed NSCLC cell metastasis, at least partially, via NF- $\mathrm{KB}$ signaling.
\end{abstract}

Correspondence to: Dr Zhe Cheng, Department of Respiratory Disease, The First Affiliated Hospital of Zhengzhou University, 1 Jianshe East Road, Zhengzhou, Henan 450000, P.R. China E-mail: zhecheng2016@163.com

Key words: forkhead box P3, non-small cell lung cancer, epithelial-mesenchymal transition, $\mathrm{NF}-\mathrm{\kappa B}$

\section{Introduction}

Lung cancer remains the leading cancer killer in developed countries with intricate etiologies and unfavorable prognosis (1). According to the statistical results of International Agency for Research on Cancer (IARC), there were around 1.8 million new lung cancer cases worldwide in 2012, accounting for $13 \%$ of all new cases (2). Surgery, radiotherapy and chemotherapy are all potential suitable treatment methods for lung cancer (3). Surgical resection is the most preferred method for lung cancer treatment and a considerable proportion of lung cancer patients could be cured by standardized tumor resection. However, surgical treatment is only suitable for the early stage (I-II period) or some III stage patients whose tumors were confined to one side of the chest (4). In addition, surgery, radiotherapy and chemotherapy can be used alone or together due to different tumor types or tumor stages. Chemotherapy is most applicable for small cell lung cancer (SCLC) while non-small cell lung cancer (NSCLC), the most common type of lung cancer, can be treated with surgery, chemotherapy, radiotherapy or a combination method depending on different tumor progression. Despite the health status of lung cancer patients have been much improved due to advanced surgical techniques and adjuvant therapy, the overall survival (OS) status of NSCLC is still unsatisfactory $(5,6)$. Targeted therapy, referring to design of appropriate treatment according to definite protein or gene target, was considered as the most effective treatment method for advanced-stage cancer patients $(7,8)$. Several lung cancer-related therapeutic targets have been identified and the targeted drugs including growth factor receptor inhibitors, angiogenesis inhibitors and signal transduction inhibitors have been put into use for lung cancer, especially for NSCLC patients (9-11). However, the clinical efficacy of these drugs remains to be validated and there is still an urgent need to investigate novel molecular targets of NSCLC.

Forkhead box P3 (Foxp3), a key member of forkhead box transcription factor family, has been considered as a remarkable modulator of regulatory T cells (Treg) $(12,13)$. Previous studies had indicated that Foxp3 gene mutation can cause severe autoimmune diseases (14). Recently, the relationship between Foxp3 and tumoral diseases has drawn much attention. Fleskens et al provided initial evidence for a novel role 
of Foxp3 as a tumor suppressor in T-cell acute lymphoblastic leukemia (T-ALL) (15). In breast cancer, Liu et al revealed that $\mathrm{miR}-146 \mathrm{a} / \mathrm{b}$ could induce cell apoptosis and contributed to Foxp3-mediated tumor suppression during tumor progress (16). These results suggested that Foxp3 may function not only as the master regulator in Tregs, but also as an X-linked tumor suppressor. However, whether Foxp3 could inhibit the aggressive behavior, especially the metastasis-associated biological process, of NSCLC is still elusive. In the present work, we explored the clinical significance of Foxp3 expression in NSCLC patients, the biological role of Foxp3 in NSCLC cell lines and the potential mechanisms.

\section{Materials and methods}

Clinical specimens. The clinical research protocol was approved by the Ethics Committee of the First Affiliated Hospital of Zhengzhou University, Zhengzhou University School of Medicine. Specimens for construction of tissue microarrays were derived from lung cancer patients who underwent curative resection at the First Affiliated Hospital of Zhengzhou University, Zhengzhou University School of Medicine. Inclusion criteria were: resectable lung cancers; without neoadjuvant chemoradiotherapy; without evidences of primary tumors of other organs; patients able to be interviewed during the follow-up. Fresh tissues were cut in wedge shapes and stored in liquid nitrogen immediately or fixed with formaldehyde for immunohistochemistry assay. Patients in prognostic group $(n=99)$ were followed until October 2011, and follow-up range was 1-69 months. OS was defined as interval between surgery and death or between surgery and the last observation point.

Immunohistochemistry and scoring. A tissue microarray block containing tumor samples and pared normal tissues was constructed. Immunostaining scores were independently evaluated by two pathologists who were blinded to clinical outcome. Integrated optical density (IOD) was counted and measured by using Image-Pro Plus v6.0 software (Media Cybernetics, Inc., Bethesda, MD, USA) from three photographs per specimen.

Scoring was performed by two researchers independently, and discrepancies were resolved by consensus with an additional investigator. Intensity of staining was categorized as 0-3 representing negative $(-)$, weak $(+)$, moderate $(++)$, and strong $(+++)$ staining, respectively. Extent of immunostaining was categorized into $0(<10 \%), 1(10-25 \%), 2(25-50 \%)$, $3(>50 \%)$. The final score of each section was determined by multiplying score of stained cell numbers with score of staining intensity, ranging from 0-9, and scores of 0-3 represent low expression level of Foxp3 and 4-9 represent high level. IOD of each photograph was evaluated by using Image Pro-Plus software according to published literature $(17,18)$.

Cell culture. Human lung squamous cell carcinoma cell line H520 was purchased from American Type Culture Collection (ATCC; Manassas, VA, USA) and lung adenocarcinoma cell line A549 was obtained from the Institute of Biochemistry and Cell Biology, Shanghai Institutes for Biological Sciences, Chinese Academy of Sciences (Shanghai, China). All cells were cultured in Dulbecco's modified Eagle's medium (DMEM) containing $10 \%$ fetal bovine serum (FBS) at $37^{\circ} \mathrm{C}$ and $5 \% \mathrm{CO}_{2}$.

Transient transfection and cell proliferation assay. For transient transfection assay, cells were seeded in 6-well culture plates at an appropriate density. Then cells were transfected with siRNAs or plasmids with Lipofectamine 2000 (Invitrogen, Carslbad, CA, USA) at 60-70\% confluence. qRT-PCR and western blot assay were used to examine transfection efficiency. Cell function analysis was conducted $48 \mathrm{~h}$ after transfection. Number of viable cells was determined by 3-(4,5-dimethylthiazol-2-yl)-2,5-diphenyltetrazolium bromide (MTT) assays (EZ4U; Biomedica, Vienna, Austria).

$R N A$ isolation and $q R T-P C R$. Total RNAs were extracted with TRIzol reagent according to the manufacturer's instructions. cDNA was synthesized using PrimeScript RT Master Mix (RR036A; Takara, Dalian, China). The expression level of target genes were detected by real-time qRT-PCR using SYBR-Green PCR Master Mix (Invitrogen) on the Applied Biosystems 7900HT sequence detection system. The relative mRNA levels (fold-change) of the specific genes were analyzed by the $2^{-\Delta \Delta \mathrm{Ct}}\left(\Delta \mathrm{Ct}=\mathrm{Ct}_{\text {target }}-\mathrm{Ct}_{\mathrm{GAPDH}} ; \Delta \Delta \mathrm{Ct}=\Delta \mathrm{Ct}_{\text {expressing }}\right.$ vector $\left.-\Delta \mathrm{Ct}_{\text {control vector }}\right)$ method. The primers were listed in Table I.

Immunoprecipitation (IP) and western blot assay. For IP assay, $2 \mu \mathrm{g}$ corresponding antibodies were immunoprecipitated with cell lysates at $4^{\circ} \mathrm{C}$ overnight. Then the IP lysates were incubated with protein $\mathrm{A} / \mathrm{G}$ agarose (Invitrogen) for $4 \mathrm{~h}$ and centrifuged for western blot assay. For western blot analysis, RIPA buffer containing PMSF (both from Solarbio, Beijing, China) and protease inhibitor cocktail (Roche Applied Science, Mannheim, Germany) were used to extract total tissue and cell proteins. Western blot analysis was done according to the standard protocol, with primary antibodies against Foxp3 (Abcam, Cambridge, MA, USA), ZO-1 and vimentin (both from CST, Beverly, MA, USA), LMO2 (Abcam). The signaling pathway antibodies were purchased from CST. GAPDH (Santa Cruz Biotechnology, Inc., Santa Cruz, CA, USA) on the same membrane was used as a loading control.

Cell migration and invasion assay. Transwell with or without Matrigel was employed for migration and invasion assay, respectively. Briefly, cells were resuspended and added into the upper chamber of Transwell at a density of $1 \times 10^{5}$ cells/well. The upper chamber was added with $200 \mu 1$ serum-free DMEM and the lower chamber was added with $600 \mu 1$ DMEM containing $10 \% \mathrm{FBS}$. After incubation at $37^{\circ} \mathrm{C}$ for 24 (migration assay) or $48 \mathrm{~h}$ (invasion assay), inserts were taken out and cells attached inside the chambers were rubbed off softly and stained with $0.1 \%$ crystal violet. Then stained cells of 5 random fields were counted.

Statistical analysis. SPSS 15.0 software was employed for statistical analysis. The correlation between clinicopathological parameters with Foxp3 expression was examined by Pearson's correlation analysis. The effect of Foxp3 on survival was estimated by Kaplan-Meier curve and log-rank test. Student's t-test was used to analyze differences between two 
Table I. Sequences of oligonucleotides used in this study.

\begin{tabular}{|c|c|}
\hline Name & Sequences $\left(5^{\prime}-3^{\prime}\right)$ \\
\hline GAPDH & $\begin{array}{l}\text { F: 5'-AGCCACATCGCTCAGACAC-3' } \\
\text { R: 5'-GCCCAATACGACCAAATCC-3' }\end{array}$ \\
\hline Foxp3 & $\begin{array}{l}\text { F: 5'-GTGGCCCGGATGTGAGAAG-3' } \\
\text { R:5'-GGAGCCCTTGTCGGATGATG-3' }\end{array}$ \\
\hline Vimentin & $\begin{array}{l}\text { F: 5'-GCCCTAGACGAACTGGGTC-3' } \\
\text { R: 5'-GGCTGCAACTGCCTAATGAG-3' }\end{array}$ \\
\hline $\mathrm{ZO}-1$ & $\begin{array}{l}\text { F: 5'-CGGTCCTCTGAGCCTGTAAG-3' } \\
\text { R: 5'-GGATCTACATGCGACGACAA-3' }\end{array}$ \\
\hline E-cadherin & $\begin{array}{l}\text { F: 5'-CGAGAGCTACACGTTCACGG-3' } \\
\text { R: 5'-GGGTGTCGAGGGAAAAATAGG-3' }\end{array}$ \\
\hline Slug & $\begin{array}{l}\text { F: 5'-AGCAGTTGCACTGTGATGCC-3' } \\
\text { R: 5'-ACACAGCAGCCAGATTCCTC-3' }\end{array}$ \\
\hline $\mathrm{N}$-cadherin & $\begin{array}{l}\text { F: 5'-TTTGATGGAGGTCTCCTAACACC-3 } \\
\text { R: 5'-ACGTTTAACACGTTGGAAATGTG-3 }\end{array}$ \\
\hline Laminin & $\begin{array}{l}\text { F: 5'-AGGAACCCGAGTTCAGCTAC-3' } \\
\text { R: 5'-CACGTCGAGGTCACCGAAAG-3' }\end{array}$ \\
\hline Snail & $\begin{array}{l}\text { F: 5'-ACTGCGACAAGGAGTACACC-3' } \\
\text { R: 5'-GAGTGCGTTTGCAGATGGG-3' }\end{array}$ \\
\hline ZEB-1 & $\begin{array}{l}\text { F: 5'-ACCTCTTCACAGGTTGCTCCT-3' } \\
\text { R: 5'-AGTGCAGGAGCTGAGAGTCA-3' }\end{array}$ \\
\hline$\beta$-catenin & $\begin{array}{l}\text { F: 5'-GATTTGATGGAGTTGGACATGG-3' } \\
\text { R: 5'-TGTTCTTGAGTGAAGGACTGAG-3' }\end{array}$ \\
\hline LMO2 & $\begin{array}{l}\text { F: 5'-GCTCCTTGAAATCGACCAGAA-3' } \\
\text { R: 5'-GCGAGTCTGTTCGGTGATGT-3' }\end{array}$ \\
\hline TAL1 & $\begin{array}{l}\text { F: 5'-CCCAACGCCAACTGGAGATTT-3' } \\
\text { R: 5'-AGTCGGATGGTCTTCTCAGTC-3' }\end{array}$ \\
\hline p53 & $\begin{array}{l}\text { F: 5'-ACTTGTCGCTCTTGAAGCTAC-3' } \\
\text { R: 5'-GATGCGGAGAATCTTTGGAACA-3' }\end{array}$ \\
\hline CD44 & $\begin{array}{l}\text { F: 5'-CTGCCGCTTTGCAGGTGTA-3' } \\
\text { R:5'-CATTGTGGGCAAGGTGCTATT-3' }\end{array}$ \\
\hline RUNX1 & $\begin{array}{l}\text { F: 5'-TGAGCTGAGAAATGCTACCGC-3' } \\
\text { R: 5'-ACTTCGACCGACAAACCTGAG-3' }\end{array}$ \\
\hline
\end{tabular}

F, forward; R, reverse.

groups and one-way ANOVA was employed for analyzing data more than two groups. $\mathrm{p}<0.05$ was considered statistically significant.

\section{Results}

Downregulated expression of Foxp 3 predicts adverse outcomes for NSCLC patients. To clarify the role of Foxp3 in NSCLC, we first evaluated the level of Foxp3 in 74 paired human NSCLC tissues and corresponding non-tumoral tissues. As shown in Fig. 1A, the mRNA level of Foxp3 was significantly downregulated in NSCLC tissues compared with non-tumoral tissues, which was confirmed by the result of western blot analysis in Fig. 1B. Next, a tissue microarray was employed to explore the relationship between Foxp3 expression and clinicopathological parameters of NSCLC patients. Foxp3 expression was significantly decreased in higher stage NSCLC patients $(n=41)$ compared with lower stage samples ( $\mathrm{n}=37$ ) (Fig. 1C and D), suggesting the role of Foxp3 in tumor progress. Additionally, as shown Fig. 1E in and calculated in Fig. 1F, patients with low expression of Foxp3 yielded worse OS than those with high expression of Foxp3. These data indicated that low expression of Foxp3 predicted adverse outcomes of NSCLC patients.

Foxp3 regulates proliferation, migration and invasion ability of NSCLC cells. We next explored the biological roles of Foxp3 in a lung squamous cell carcinoma cell line H520 and a lung adenocarcinoma cell line A549. Two commercialized siRNAs were employed for silencing of FOXP3 in H520 and A549 cells. As indicated in Fig. 2A, both siRNAs downregulated the expression of Foxp3 effectively and siRNA\#2 yielded a more effective silencing efficiency. We found that the proliferation ability of A549 cells was enhanced after silencing of FOXP3 (Fig. 2B) and observed that the migrated cells through Transwell were significantly increased after silencing of FOXP3 (Fig. 2C). In addition, silencing of FOXP3 promoted the proliferation, migration and invasion ability of H520 cells (Fig. 2D-F). To confirm the biological results of Foxp3 inhibition, Foxp3 overexpression plasmid pcDNA3.1-Foxp3 and the control plasmid were transiently transfected into A549 cells. The transfection efficiency was examined by western blot analysis and pcDNA3.1-Foxp3 group yield a restoration effect of Foxp3 (Fig. 3A). The MTT assay indicated that Foxp3 restoration undermined the proliferation ability of A549 cells and the Transwell analysis suggested that overexpression of Foxp3 inhibited the migration and invasion ability of A549 cells (Fig. 3B and C). These results indicated that Foxp3 could regulate proliferation, migration and invasion ability of NSCLC cells.

Foxp3 regulates epithelial-mesenchymal transition (EMT) of NSCLC cells. To clarify the preliminary mechanism of Foxp3 mediated biological behavior, we next detected the expression level of EMT makers involved in the self-renewal ability, especially in migration and invasion process. EMT markers including vimentin, ZO-1, E-cadherin, Slug, N-cadherin, laminin, Snail, ZEB-1 and $\beta$-catenin were chosen for analysis according to published literature. Furthermore, by screening Foxp3-related literature, we selected 5 most relevant genes involved in Foxp3-mediated diseases, especially cancer-related diseases. By examining the mRNA level of these genes, We observed a downregulation of epithelial marker ZO-1 and an upregulation of mesenchymal marker vimentin after Foxp3 downregulation (Fig. 3D), which were confirmed by the results of western blot analysis (Fig. 3E). Additionally, the mRNA level of LMO2 was decreased while the level of TAL1 was increased after silencing of FOXP3 (Fig. 3D), which was accompanied with the expression change of the two genes induced by Foxp3 downregulation in T-ALL.

Foxp3 regulates $N F-\kappa B$ signaling in NSCLC cells. We next explored the mechanisms of Foxp3 regulation of EMT in NSCLC cells. In a recently published study (15), Foxp3 func- 
A

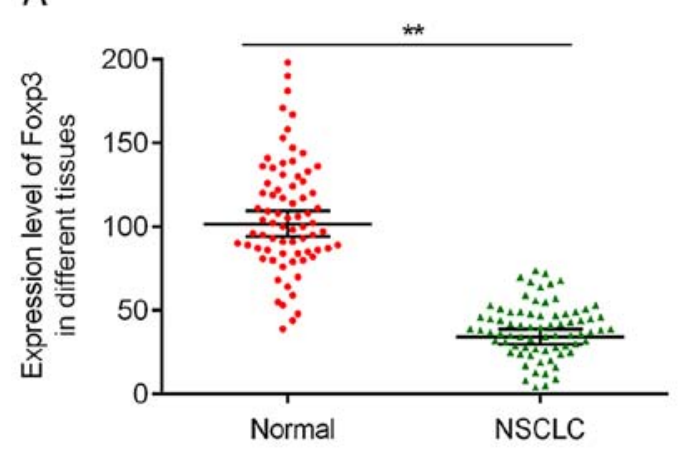

C

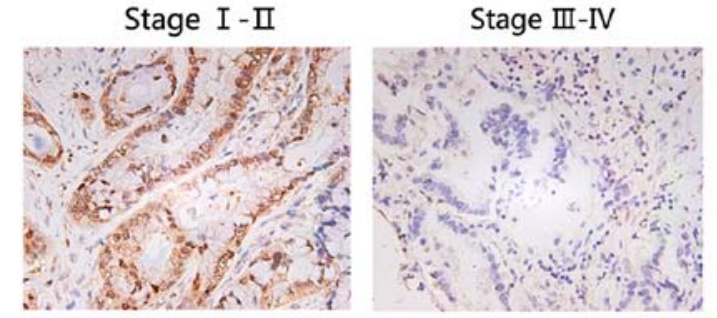

$\mathrm{E}$
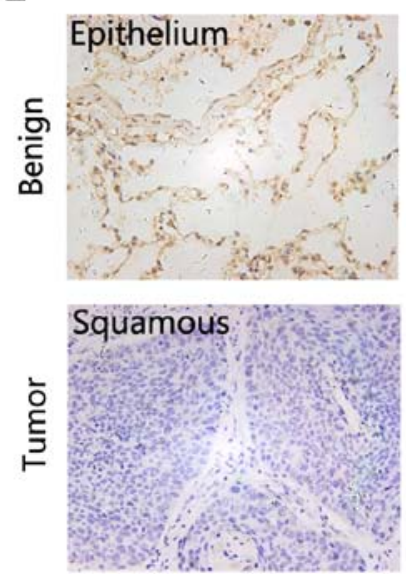

B
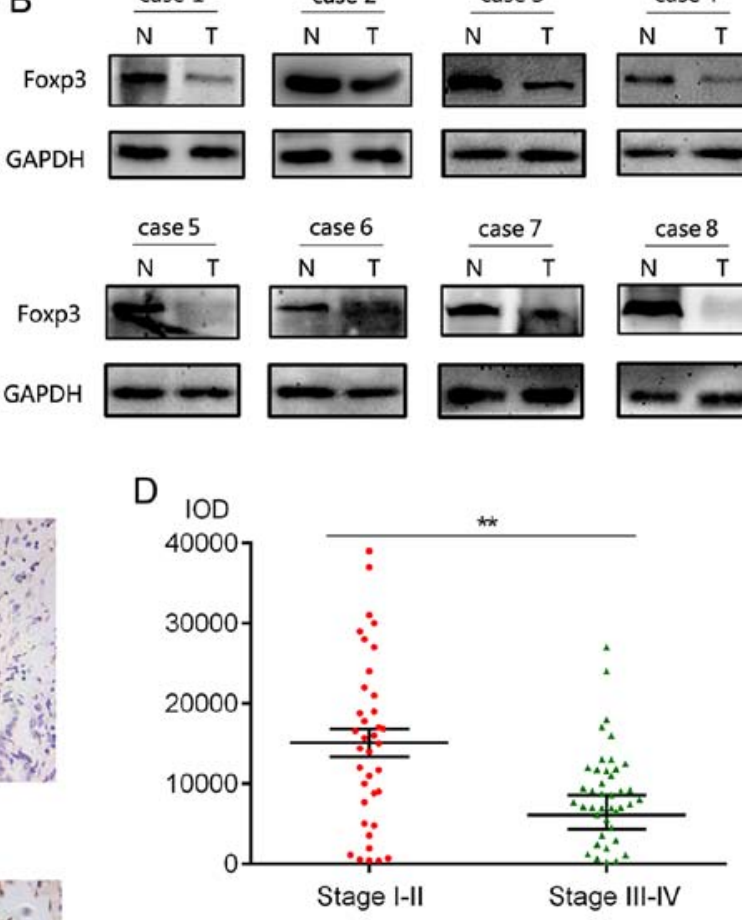

$\mathrm{F}$

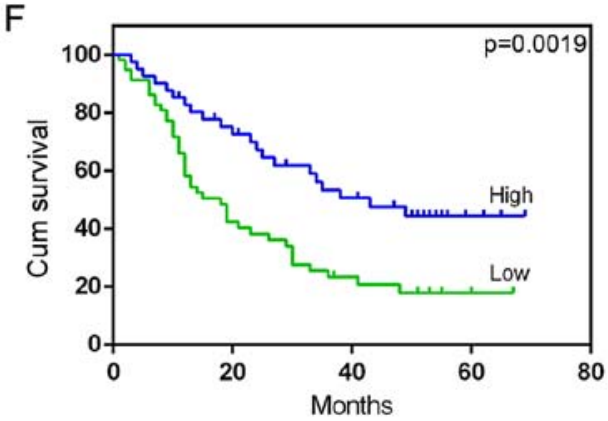

Figure 1. Downregulation of forkhead box P3 (Foxp3) in tumor tissues predicted adverse outcomes of non-small cell lung cancer (NSCLC) patients. (A and B) Foxp3 was downregulated in NSCLC tissues by qRT-PCR and western blot assay respectively. GAPDH was used as an endogenous control. (C) Representative pictures of different stage NSCLC tissues. (D) Foxp3 expression was significantly decreased in higher stage NSCLC patients compared with lower stage samples. (E) Immunohistochemical staining of Foxp3 in: benign epithelium, alveolar, squamous carcinoma and adenocarcinoma patients. (F) Overall survival between patients with low and high Foxp3 expression. ${ }^{* *} \mathrm{p}<0.01$.

tioned as a tumor suppressor of T-ALL modulating TAL1 transcriptional activity through interaction with LMO2. We verified the endogenous interaction between LMO2 and Foxp3 by co-IP (Fig. 4A and B). Additionally, the mRNA level of TAL1 was significantly upregulated after silencing of FOXP3 (Fig. 4C), suggesting a similar mechanism through which Foxp3 regulated biological behavior of NSCLC cells. The in-depth mechanisms of these results needed to be confirmed by further studies.

Considering the different pathogenesis and molecular mechanisms between T-ALL and NSCLC, we determined to explore novel mechanisms on Foxp3-mediated EMT. Published literature has revealed that ERK, PI3K, Jak and $\mathrm{NF}-\kappa \mathrm{B}$ signaling pathways were all potential regulatory factors involved in EMT (19-22). In the present study, we detected the expression level of ERK, PI3K, Jak, NF- $\kappa \mathrm{B}$ and their corresponding phosphorylated proteins. As the result, silencing of
FOXP3 increased the phospho-NF- $\mathrm{B}$ level in both cell lines while higher $\mathrm{p}$-ERK42/44 ${ }^{\mathrm{Thr} 202 / \mathrm{Tyr} 2}$ was detected in only one cell line (Fig. 4D). These results suggested that Foxp3 could regulate EMT, at least partially, via $\mathrm{NF}-\kappa \mathrm{B}$ pathway.

\section{Discussion}

Foxp3 gene localized at $\mathrm{X}$ chromosome and three domains of Foxp3 protein have been identified so far: an N-terminal $\mathrm{C} 2 \mathrm{H} 2$ Zinc finger domain, a leucine zipper motif and a conserved C-terminal forkhead DNA-binding region (FKH) $(23,24)$. Although high Foxp3 levels are initially detected in Tregs, the expression of Foxp3 is not restricted to Tregs. Recent studies indicated that Foxp3 was also expressed in breast, lung, prostate and gastric cancer tissue (25-28). Furthermore, the clinical roles and biological function of Foxp3 have been thoroughly studied in T-ALL and breast cancer $(15,27)$. These results 

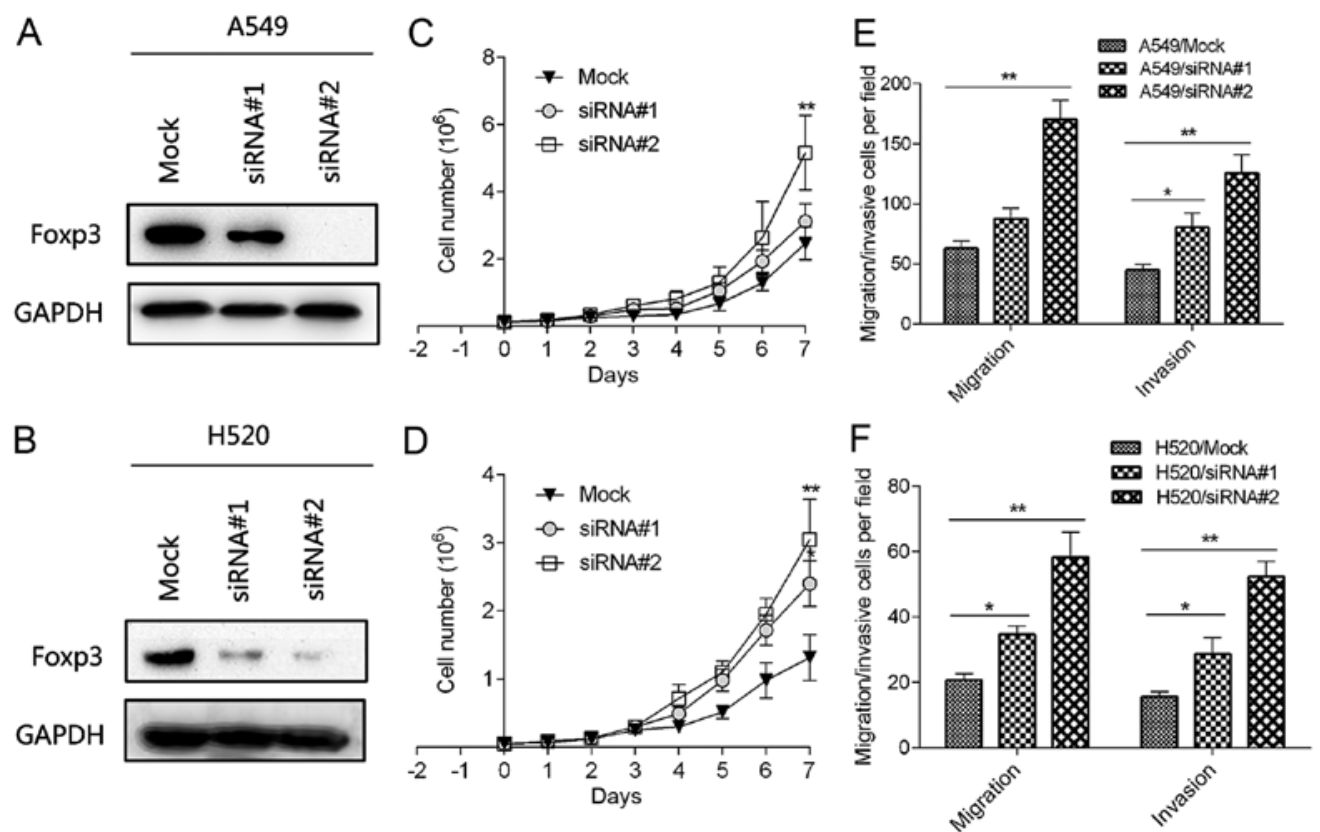

Figure 2. Silencing of forkhead box P3 (FOXP3) promoted the proliferation, migration and invasion ability of non-small cell lung cancer (NSCLC) cells. (A and B) The silencing efficiency by targeted siRNAs were verified by western blot assay. Both siRNAs showed downregulation effect and siRNA\#2 yielded a better silencing efficiency. (C and D) Silencing of FOXP3 in A549 cells and H520 cells promoted the cell proliferation ability respectively. (E and F) Cell invasion and migration ability were increased in Foxp3 knockdown A549 and H520 cells. ${ }^{*} \mathrm{p}<0.05,{ }^{* *} \mathrm{p}<0.01$.

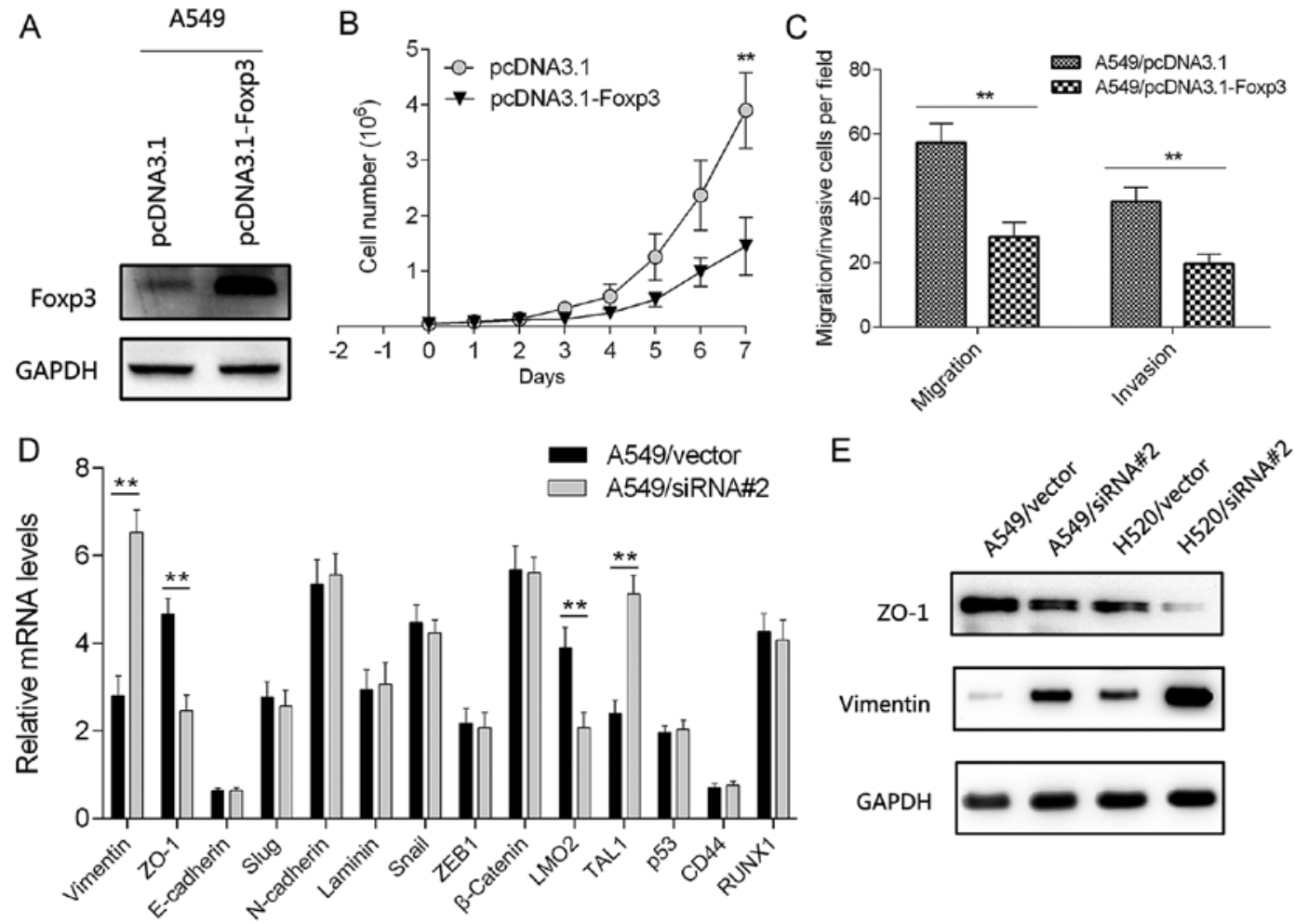

Figure 3. (A-C) Forkhead box P3 (Foxp3) restoration inhibited the proliferation, migration and invasion ability of A549 cells. (D) qRT-PCR analysis of epithelial-mesenchymal transition (EMT)-related genes indicated that the mRNA level of epithelial marker ZO-1 was downregulated while the level of mesenchymal marker vimentin was upregulated after silencing of FOXP3. GAPDH was used as an endogenous control. (E) The protein level of ZO-1 was downregulated while the level of vimentin was upregulated after silencing of FOXP3. ${ }^{* *} \mathrm{p}<0.01$.

revealed Foxp3 could induce tumor suppressor phenotypes in human cancer. Although a variety of Foxp3-related signaling pathways had been identified in Treg cells, the mechanisms of Foxp3-assiociated cancers were not entirely clear.
In the present study, we first evaluated the clinical significance of Foxp3 expression in NSCLC patients. The results of the qRT-PCR and western blot analysis showed that Foxp3 was decreased in NSCLC tissues compared with non-tumoral 


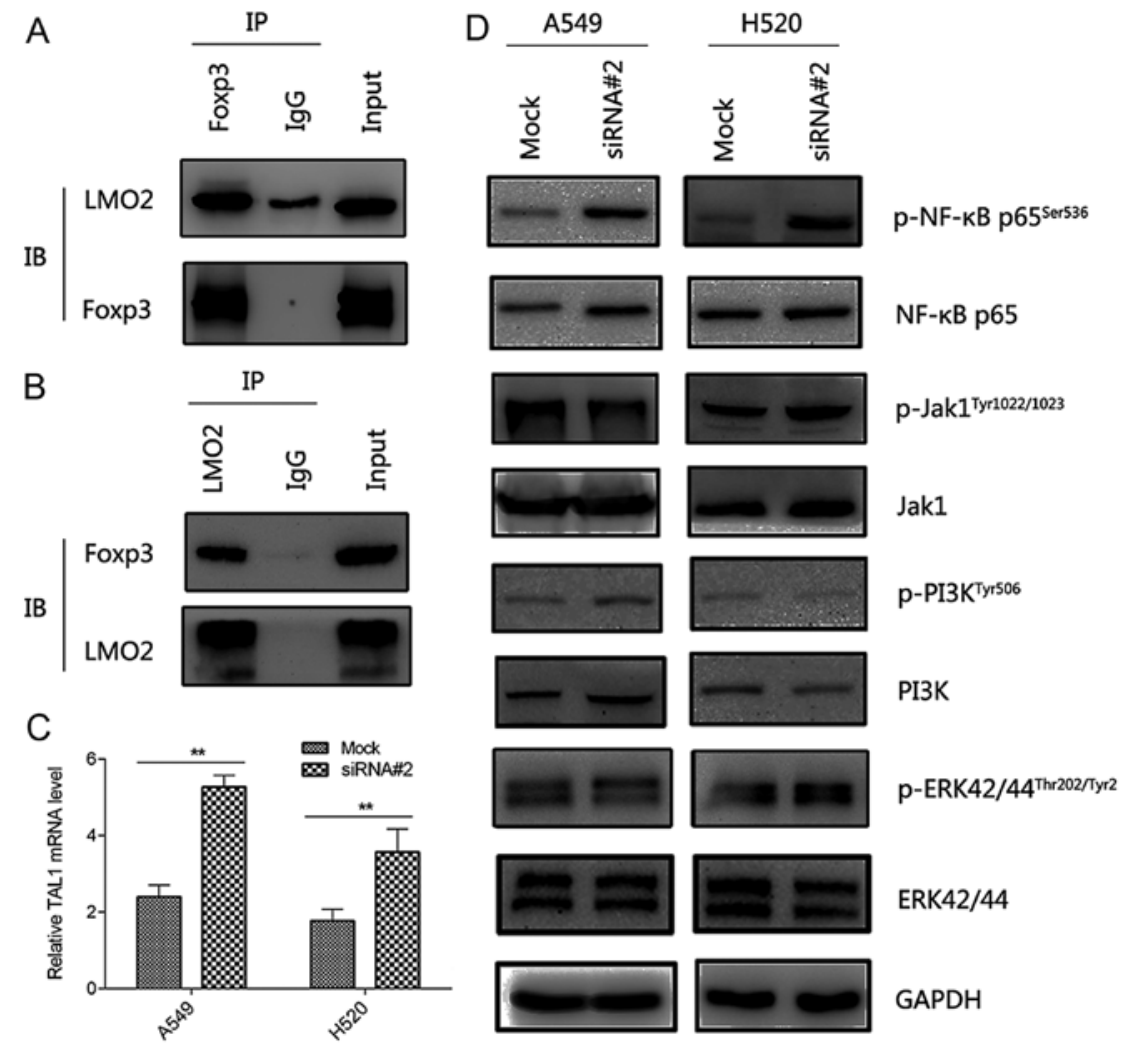

Figure 4. (A-C) Forkhead box P3 (Foxp3) could interact with LMO2 and silencing of FOXP3 promoted the mRNA level of TAL1. GAPDH was used as an endogenous control. (D) Foxp3 regulated NF-кB pathway in non-small cell lung cancer (NSCLC) cells. ERK42/44, p-ERK42/44, PI3K, p-PI3K, Jak1, p-Jak1, $\mathrm{NF}-\mathrm{\kappa B}$ and p-NF- $\mathrm{kB}$ levels were detected by western blot analysis. p-ERK42/44 was upregulated in H520 cells after silencing of FOXP3 while p-NF- $\mathrm{kB}$ was upregulated in both cell lines. ${ }^{* *} \mathrm{p}<0.01$.

tissues. In addition, a tissue microarray block was constructed for evaluating the relationship between Foxp3 expression and the clinicopathological parameters of NSCLC patients. As the result, lower stage NSCLC samples tended to have higher Foxp3 expression compared with higher stage patients. Higher Foxp3 expression predicted shorter OS in NSCLC patients. These results indicated that high expression level of Foxp3 predicted adverse outcomes of NSCLC patients.

The role of Foxp3 in NSCLC cell proliferation has not been thoroughly discussed before. In our study, we found that transfection of targeted siRNA into A549 and H520 cells promoted cell proliferation while Foxp3 re-expression in A549 cells inhibited cell proliferation, suggesting potential tumor-suppressive role of Foxp3. EMT refers to a complex biological process during which polarized epithelial cells connected to the basement membrane obtained the phenotypes of mesenchymal cells $(29,30)$. These phenotypes include enhanced migration, invasion, anti-apoptotic ability, as well as a significant increase of the extracellular matrix (30). In the microscopic view, the essence of EMT process is the decrease of epithelial markers including E-cadherin, laminin and the increase of representative mesenchymal markers including Snail, Slug, N-cadherin and vimentin $(30,31)$. Recent evidences indicated that the EMT process was involved in the development of pulmonary adenocarcinoma and squamous cell carcinoma $(32,33)$. In the present study, EMT-related aggressive behavior including migration and invasion were promoted after Foxp3 downregulation while these phenotypes were inhibited by Foxp3 restoration. Additionally, the mRNA and protein levels of epithelial marker ZO-1 was downregulated while the levels of mesenchymal marker vimentin was upregulated in A549/ siRNA\#2 cells compared with A549/vector cells. These results indicated that Foxp3 was an upstream regulator of EMT process in NSCLC cells. However, the definite role of Foxp3 in EMT regulation requires further study.

We next explored the mechanisms of Foxp3 regulation of the EMT process. Recent literature revealed that Foxp3 could modulate TAL1 transcriptional activity through interaction with LMO2 in T-ALL (15). In the present study, we found Foxp3 could interacted with LMO2 by co-IP assay, furthermore, we observed that the mRNA level of TAL1 was upregulated in both cell lines after Foxp3 downregulation. These results indicated that Foxp 3 could interact with LMO2 and affect the expression level of TAL1, suggesting a potential mechanism of Foxp3-mediated EMT. However, these results still needed to be confirmed and further studied due to the different pathogenesis and molecular mechanisms between NSCLC and T-ALL. By screening ERK, PI3K, Jak and NF- $\kappa \mathrm{B}$ signaling pathways, we found that protein level of p-ERK42/44 ${ }^{\mathrm{Thr} 202 / \mathrm{Tyr} 2}$ was increased in squamous cell carcinoma cell line H520 while no significance of p-ERK42/44 ${ }^{\mathrm{Th} 202 / \mathrm{Tyr} 2}$ level was observed in adenocarcinoma cell line A549. These results indicated the different molecular mechanisms between lung squamous cell carcinoma and adenocarcinoma, which still needed further investigation. Interestingly, we observed that silencing of FOXP3 increased the phospho-NF- $\mathrm{B}$ level in both cell lines, which was accompanied by the relationship between $\mathrm{NF}-\kappa \mathrm{B}$ 
pathway and EMT process in breast cancer, pancreatic cancer, gastric cancer and other cancer types $(22,34,35)$.

In conclusion, we identified the tumor suppressive role of Foxp3 in NSCLC. Low expression level Foxp3 predicted adverse outcomes of NSCLC patients. Foxp3 could regulate the EMT process of NSCLC, at least partially, via NF- $\mathrm{BB}$ pathway. This study provided novel insights into the role of FOXP3 in NSCLC and expanded the growing understanding of NSCLC biology.

\section{Acknowledgements}

This study was supported by the Youth Innovation Fund of the First Affiliated Hospital of Zhengzhou University.

\section{References}

1. Ferlay J, Soerjomataram I, Dikshit R, Eser S, Mathers C, Rebelo M, Parkin DM, Forman D and Bray F: Cancer incidence and mortality worldwide: Sources, methods and major patterns in GLOBOCAN 2012. Int J Cancer 136: E359-E386, 2015.

2. Torre LA, Bray F, Siegel RL, Ferlay J, Lortet-Tieulent J and Jemal A: Global cancer statistics, 2012. CA Cancer J Clin 65 : 87-108, 2015.

3. Lemjabbar-Alaoui H, Hassan OU, Yang YW and Buchanan P: Lung cancer: Biology and treatment options. Biochim Biophys Acta 1856: 189-210, 2015

4. Howington JA, Blum MG, Chang AC, Balekian AA and Murthy SC: Treatment of stage I and II non-small cell lung cancer: Diagnosis and management of lung cancer, 3rd ed American College of Chest Physicians evidence-based clinical practice guidelines. Chest 143 (Suppl 5): e278S-e313S, 2013

5. Inoue A, Kobayashi K, Maemondo M, Sugawara S, Oizumi S, Isobe H, Gemma A, Harada M, Yoshizawa H, Kinoshita I, et al; North-East Japan Study Group: Updated overall survival results from a randomized phase III trial comparing gefitinib with carboplatin-paclitaxel for chemo-naïve non-small cell lung cancer with sensitive EGFR gene mutations (NEJ002). Ann Oncol 24: 54-59, 2013.

6. Siegel R, Naishadham D and Jemal A: Cancer statistics, 2013. CA Cancer J Clin 63: 11-30, 2013.

7. Sawyers C: Targeted cancer therapy. Nature 432: 294-297, 2004.

8. Gray-Schopfer V, Wellbrock C and Marais R: Melanoma biology and new targeted therapy. Nature 445: 851-857, 2007.

9. Kris MG, Natale RB, Herbst RS, Lynch TJ Jr, Prager D, Belani CP, Schiller JH, Kelly K, Spiridonidis H, Sandler A, et al: Efficacy of gefitinib, an inhibitor of the epidermal growth factor receptor tyrosine kinase, in symptomatic patients with non-small cell lung cancer: A randomized trial. JAMA 290: 2149-2158, 2003.

10. Janku F, Stewart DJ and Kurzrock R: Targeted therapy in non-small-cell lung cancer - is it becoming a reality? Nat Rev Clin Oncol 7: 401-414, 2010.

11. Antonicelli A, Cafarotti S, Indini A, Galli A, Russo A, Cesario A, Lococo FM, Russo P, Mainini AF, Bonifati LG, et al: EGFR-targeted therapy for non-small cell lung cancer: Focus on EGFR oncogenic mutation. Int J Med Sci 10: 320-330, 2013.

12. Arvey A, van der Veeken J, Samstein RM, Feng Y, StamatoyannopoulosJA and Rudensky AY: Inflammation-induced repression of chromatin bound by the transcription factor Foxp3 in regulatory T cells. Nat Immunol 15: 580-587, 2014.

13. Samstein RM, Arvey A, Josefowicz SZ, Peng X, Reynolds A, Sandstrom R, Neph S, Sabo P, Kim JM, Liao W, et al: Foxp3 exploits a pre-existent enhancer landscape for regulatory $\mathrm{T}$ cell lineage specification. Cell 151: 153-166, 2012.

14. Katoh H, Zheng P and Liu Y: FOXP3: Genetic and epigenetic implications for autoimmunity. J Autoimmun 41: 72-78, 2013.

15. Fleskens V, Mokry M, van der Leun AM, Huppelschoten S, Pals CE, Peeters J, Coenen S, Cardoso BA, Barata JT, van Loosdregt J, et al: FOXP3 can modulate TAL1 transcriptional activity through interaction with LMO2. Oncogene: Dec 21, 2015 (Epub ahead of print).

16. Liu R, Liu C, Chen D, Yang WH, Liu X, Liu CG, Dugas CM, Tang F, Zheng P, Liu Y, et al: Foxp3 controls an miR-146/NF- $\mathrm{B}$ negative feedback loop that inhibits apoptosis in breast cancer cells. Cancer Res 75: 1703-1713, 2015.
17. Zhao D, Long XD, Lu TF, Wang T, Zhang WW, Liu YX, Cui XL, Dai HJ, Xue F and Xia Q: Metformin decreases IL-22 secretion to suppress tumor growth in an orthotopic mouse model of hepatocellular carcinoma. Int J Cancer 136: 2556-2565, 2015.

18. Luo Q, Zhang Y, Wang N, Jin G, Jin H, Gu D, Tao X, Huo X, Ge $\mathrm{T}$, Cong $\mathrm{W}$, et al: Leukemia inhibitory factor receptor is a novel immunomarker in distinction of well-differentiated HCC from dysplastic nodules. Oncotarget 6: 6989-6999, 2015.

19. Suh Y, Yoon CH, Kim RK, Lim EJ, Oh YS, Hwang SG, An S, Yoon G, Gye MC, Yi JM, et al: Claudin-1 induces epithelial-mesenchymal transition through activation of the c-Abl-ERK signaling pathway in human liver cells. Oncogene 32 : 4873-4882, 2013.

20. Schlegel NC, von Planta A, Widmer DS, Dummer R and Christofori G: PI3K signalling is required for a TGF $\beta$-induced epithelial-mesenchymal-like transition (EMT-like) in human melanoma cells. Exp Dermatol 24: 22-28, 2015.

21. Liu R-Y, Zeng Y, Lei Z, Wang L, Yang H, Liu Z, Zhao J and Zhang HT: JAK/STAT3 signaling is required for TGF- $\beta$-induced epithelial-mesenchymal transition in lung cancer cells. Int J Oncol 44: 1643-1651, 2014.

22. Li C-W, Xia W, Huo L, Lim SO, Wu Y, Hsu JL, Chao CH, Yamaguchi H, Yang NK, Ding Q, et al: Epithelial-mesenchymal transition induced by TNF- $\alpha$ requires NF- $\mathrm{kB}$-mediated transcriptional upregulation of Twist1. Cancer Res 72: 1290-1300, 2012.

23. Hori S, Nomura T and Sakaguchi S: Control of regulatory T cell development by the transcription factor Foxp3. Science 299: 1057-1061, 2003.

24. Bennett CL, Christie J, Ramsdell F, Brunkow ME, Ferguson PJ, Whitesell L, Kelly TE, Saulsbury FT, Chance PF and Ochs HD: The immune dysregulation, polyendocrinopathy, enteropathy, $\mathrm{X}$-linked syndrome (IPEX) is caused by mutations of FOXP3. Nat Genet 27: 20-21, 2001.

25. Perrone G, Ruffini PA, Catalano V, Spino C, Santini D, Muretto P, Spoto C, Zingaretti C, Sisti V, Alessandroni P, et al: Intratumoural FOXP3-positive regulatory $\mathrm{T}$ cells are associated with adverse prognosis in radically resected gastric cancer. Eur $\mathrm{J}$ Cancer 44: 1875-1882, 2008.

26. Merlo A, Casalini P, Carcangiu ML, Malventano C, Triulzi T, Mènard S, Tagliabue E and Balsari A: FOXP3 expression and overall survival in breast cancer. J Clin Oncol 27: 1746-1752, 2009.

27. Li W, Wang L, Katoh H, Liu R, Zheng P and Liu Y: Identification of a tumor suppressor relay between the FOXP3 and the Hippo pathways in breast and prostate cancers. Cancer Res 71: 2162-2171, 2011

28. Wang L, Liu R, Li W, Chen C, Katoh H, Chen GY, McNally B, Lin L, Zhou P, Zuo T, et al: Somatic single hits inactivate the $\mathrm{X}$-linked tumor suppressor FOXP3 in the prostate. Cancer Cell 16: 336-346, 2009.

29. Zavadil J, Haley J, Kalluri R, Muthuswamy SK and Thompson E: Epithelial-mesenchymal transition. Cancer Res 68: 9574-9577, 2008.

30. Lamouille S, Xu J and Derynck R: Molecular mechanisms of epithelial-mesenchymal transition. Nat Rev Mol Cell Biol 15: 178-196, 2014.

31. Gonzalez DM and Medici D: Signaling mechanisms of the epithelial-mesenchymal transition. Sci Signal 7: re8, 2014.

32. Cañadas I, Rojo F, Taus Á, Arpí O, Arumí-Uría M, Pijuan L, Menéndez S, Zazo S, Dómine M, Salido M, et al: Targeting epithelial-to-mesenchymal transition with Met inhibitors reverts chemoresistance in small cell lung cancer. Clin Cancer Res 20: 938-950, 2014

33. Serresi M, Gargiulo G, Proost N, Siteur B, Cesaroni M, Koppens M, Xie H, Sutherland KD, Hulsman D, Citterio E, et al: Polycomb repressive complex 2 is a barrier to KRAS-driven inflammation and epithelial-mesenchymal transition in non-small cell lung cancer. Cancer Cell 29: 17-31, 2016.

34. Cheng Z-X, Wang D-W, Liu T, Liu WX, Xia WB, Xu J, Zhang YH, Qu YK, Guo LQ, Ding L, et al: Effects of the HIF-1 $\alpha$ and NF- $\kappa \mathrm{B}$ loop on epithelial-mesenchymal transition and chemoresistance induced by hypoxia in pancreatic cancer cells. Oncol Rep 31: 1891-1898, 2014.

35. Li J, Deng Z, Wang Z, Wang D, Zhang L, Su Q, Lai Y, Li B, Luo Z, Chen X, et al: Zipper-interacting protein kinase promotes epithelial-mesenchymal transition, invasion and metastasis through AKT and NF- $\mathrm{BB}$ signaling and is associated with metastasis and poor prognosis in gastric cancer patients. Oncotarget 6: 8323-8338, 2015. 